\title{
Failure to demonstrate experimental vertical transmission of the epidemic strain of Chikungunya virus in Aedes albopictus from La Réunion Island, Indian Ocean
}

\author{
Marie Vazeille ${ }^{+}$, Laurence Mousson, Anna-Bella Failloux \\ Institut Pasteur, Génétique moléculaire des Bunyavirus, 25-28 rue du Dr. Roux, F-75724 Paris Cedex 15, France
}

\begin{abstract}
Aedes albopictus was responsible for transmission in the first outbreak of chikungunya (CHIK) on La Réunion Island, Indian Ocean, in 2005-2006. The magnitude of the outbreak on this island, which had been free of arboviral diseases for over 30 years, as well as the efficiency of Ae. albopictus as the main vector, raises questions about the maintenance of the CHIK virus (CHIKV) through vertical transmission mechanisms. Few specimens collected from the field as larvae were found to be infected. In this study, Ae. albopictus originating from La Réunion were orally infected with a blood-meal containing $10^{8} \mathrm{pfu} / \mathrm{mL}$ of the CHIKV epidemic strain (CHIKV 06.21). Eggs from the first and second gonotrophic cycles were collected and raised to the adult stage. The infectious status of the progeny was checked (i) by immunofluorescence on head squashes of individual mosquitoes to detect the presence of viral particles or (ii) by quantitative RT-PCR on mosquito pools to detect viral RNA. We analysed a total of 1,675 specimens from the first gonotrophic cycle and 1,709 from the second gonotrophic cycle without detecting any viral particles or viral RNA. These laboratory results are compared to field records.
\end{abstract}

Key words: vertical transmission - chikungunya virus - Aedes albopictus - La Réunion Island - Indian Ocean

Chikungunya virus (CHIKV) is a vector-borne alphavirus transmitted to humans by mosquitoes belonging to the genus Aedes. It was first isolated in 1953 in Tanzania (Ross 1956) and until recently outbreaks had only been observed in Africa, Asia and India. In Africa, CHIKV is maintained within a sylvatic cycle with wild mosquitoes as vectors (Jupp \& Kemp 1996, Diallo et al. 1999). In Asia and India, a sylvatic cycle has never been demonstrated and CHIKV is mainly transmitted within an urban cycle primarily involving the human-biting Aedes aegypti and the less anthropophilic Aedes albopictus (Jupp \& McIntosh 1988). Re-emergence of CHIKV outbreaks is unpredictable and occurs frequently after 7-8 years of silence. In March 2005, CHIKV emerged for the first time in the southwestern Indian Ocean region in the Comoro Islands, probably introduced from Kenya, where the outbreak started in 2004. The CHIKV rapidly spread to other islands in the region, including Mayotte, the Seychelles, Mauritius and La Réunion, with a major outbreak responsible for at least 266,000 cases $(1 / 3$ of the population) from November 2005-June 2006 (Renault et al. 2007). Usually considered to be a secondary vector, Ae. albopictus was proven to be responsible for the transmission of CHIKV in La Réunion. Ae. aegypti was only present in a few remote areas and was not anthropophilic

Financial support: Institut Pasteur (PTR 201), Agence Nationale pour la Recherche "ANR EntomoChik" project

+ Corresponding author: marie.vazeille@pasteur.fr

Received 23 February 2009

Accepted 26 May 2009
(Salvan \& Mouchet 1994). Interestingly, the sequencing of viral strains from La Réunion demonstrated the emergence of a mutation in the course of the outbreak and the mutation was detected in the majority of the viral population (Schuffenecker et al. 2006). This mutation was shown to be associated with a better transmission rate by Ae. albopictus (Tsetdatkin et al. 2007, Vazeille et al. 2007). Furthermore, viral particles could be detected in the salivary glands at day 2 post-infection and high densities of viral particles were observed in eggs at day 6 post-infection. This last observation raised concerns of possible maintenance of the virus on the island through vertical transmission, a mechanism by which arboviruses can be maintained in nature when climate conditions are unfavourable to the activity of adults: infected females die but the virus can survive in their desiccated eggs. The frequency of this phenomenon is extremely variable depending on the mosquito species and the virus. Vertical transmission of CHIKV has not yet been demonstrated in the laboratory (Jupp et al. 1981, Mourya 1987), but has been proven to occur in the field in Ae. albopictus, in La Réunion (Delatte et al. 2008) and in Madagascar (Ratsitorahina et al. 2008). However, the transmission rate was low and only viral RNA was detected, with no virus isolated. Therefore, we attempted to demonstrate vertical transmission under laboratory conditions with Ae. albopictus from La Réunion and the epidemic viral strain in order to assess the potential risk of maintenance of CHIKV on the island.

\section{MATERIALS AND METHODS}

Mosquitoes - The Providence Ae. albopictus strain used in this study originated from a field sample of eggs collected on La Réunion Island in March 2007 (F0). This strain has since been maintained in the laboratory at 28 
$\pm 1^{\circ} \mathrm{C}$ with $80 \%$ relative humidity and a $16: 8 \mathrm{~h}$ photoperiod. Adults were given $10 \%$ sucrose solution and females fed on a mouse to get eggs. To produce enough females of the same physiological age for oral infections, batches of eggs were hatched and larvae reared to the adult stage in pans with tap water and yeast tablets. For vertical transmission experiments, females from the second generation (F2) were used for the first assay (assay A) and F5 generation females were used for the second assay (B).

Virus - Strain 06.21 CHIKV, provided by the French National Reference Center for Arboviruses of the Institut Pasteur, was isolated on Ae. albopictus C6/36 cells (Igarashi 1978) from a serum collected in November 2005 from a new-born male from La Réunion Island. CHIKV 06.21 was the major genotype isolated from patients during the 2005-2006 outbreak and presented an A226V mutation in the $E 1$ gene (Schuffenecker et al. 2006). Viral production and titration were described by Vazeille et al. (2007).

Vertical transmission experiments - Two experiments were performed. The first one (assay A) allowed us to collect eggs from the first gonotrophic cycle of orally infected females. In the second experiment (assay B), a first non-infectious blood-meal was given to allow the oviposition of eggs from the first gonotrophic cycle before the infectious meal was provided 10 days later. This protocol was chosen since we were unable to get infected females to have a second blood-meal under the level 3 confinement insectarium (L3) conditions.

Assay A - Infection assays were performed with sevenday-old females that were allowed to feed for $15 \mathrm{~min}$ through a chicken skin membrane covering the base of a glass feeder containing the blood-virus mixture, which was maintained at $37^{\circ} \mathrm{C}$. The infectious meal was composed of a virus suspension diluted (1:3) in washed rabbit erythrocytes isolated from arterial blood collected $24 \mathrm{~h}$ before the infectious meal (Vazeille-Falcoz et al. 1999). To enhance the oviposition rate, bovine serum albumin (BSA) was added to the meal, i.e., red cells were washed in PBS then mixed with L-15 medium complemented with $10 \%$ BSA. Phagostimulant ATP was added at a final concentration of $5 \times 10^{-3} \mathrm{M}$. To ensure a high rate of disseminated infection of females, a titre of $10^{8}$ plaque-forming units (pfu) $/ \mathrm{mL}$ was used in the meal. It has been shown that this titre ensures a disseminated infection rate of $100 \%$ in Ae. albopictus females from La Réunion (Vazeille et al. 2007).

Fully engorged females were transferred to individual tubes and maintained with $10 \%$ sucrose at $28 \pm$ $1^{\circ} \mathrm{C}$ until death. Filter papers were wetted two days after the blood-meal to allow oviposition. Eggs were collected and kept in the L3 confinement laboratory, where they were hatched and reared to the adult stage with a $16: 10$ $\mathrm{h}$ photoperiod.

Assay B - Under the L 3 confinement conditions in which the infected females were kept, we were unable to get Ae. albopictus females to take a second blood-meal after they had laid their eggs from the first gonotrophic cycle and this despite numerous attempts. We therefore made the choice to offer a first non-infectious meal in a regular insectarium and then, after the females had laid their first batch of eggs (10 days later), to bring them to L3 confinement for the infectious meal and collect the eggs from the second gonotrophic cycle. Provision of infectious blood-meals and collection of progeny were performed as in assay A.

Viral detection in progeny - In assay A, the infected status of the progeny was tested by two means: (i) the presence of CHIKV was checked by indirect immunofluorescence on head squashes (Kubersky \& Rosen 1977) using a mouse ascetic fluid provided by the French National Reference Center for Arboviruses of the Institut Pasteur and (ii) bodies were pooled per family and sex, with a maximum of 15 specimens per pool, to check for the presence of viral RNA in these pools by quantitative RT-PCR. In assay B, the presence of viral RNA was checked in whole mosquitoes pooled by family and sex with no more than 10 specimens per pool. A family consisted of the progeny of one infected female.

Quantitative RT-PCR analysis - Total RNA was extracted using the Nucleospin ${ }^{\circledR}$ RNA II kit (MachereyNagel), following the manufacturer's instructions. All procedures were previously described by Vazeille et al. (2007). The one-step RT-PCR was performed with a Power SYBR ${ }^{\circledR}$ Green RNA-to-CT ${ }^{\mathrm{TM}}$ one step kit (Applied Biosystem) in a volume of $25 \mu \mathrm{L}$ containing 2 $\mu \mathrm{L}$ RNA template, $12.5 \mu \mathrm{L} 2 \mathrm{X}$ Power $\mathrm{SYBR}^{\circledR}$ Green I RT-PCR Mix, $0.25 \mu \mathrm{L}$ sense $(2.5 \mu \mathrm{M})$ primer, $0.25 \mu \mathrm{L}$ anti-sense $(2.5 \mu \mathrm{M})$ primer and $0.2 \mu \mathrm{L}$ RT enzyme mix. Primers were selected from the E2 structural protein regions of sequences retrieved from the GenBank database by the Laboratory for Urgent Response to Biological Threats at the Institut Pasteur: sense Chik/E2/9018/+ (CACCGCCGCAACTACCG) and anti-sense Chik/ E2/9235/- (GATTGGTGACCGCGGCA). The amplification program in an Applied Biosystem 7700 real-time PCR system consisted of: reverse transcription at $48^{\circ} \mathrm{C}$ for $30 \mathrm{~min}$, an activation step of the polymerase at $95^{\circ} \mathrm{C}$ for $10 \mathrm{~min}$, followed by 40 cycles of $95^{\circ} \mathrm{C}$ for $15 \mathrm{~s}, 60^{\circ} \mathrm{C}$ for $1 \mathrm{~min}, 72^{\circ} \mathrm{C}$ for $30 \mathrm{~s}$ and $95^{\circ} \mathrm{C}$ for $20 \mathrm{~s}$ and a final ramping step lasting $19 \mathrm{~min} 59 \mathrm{~s}$. The size of the amplification product was $217 \mathrm{bp}$. After amplification, a melting curve was acquired to check the specificity of the PCR products. Each pool was analysed in duplicate. Signals were normalised to the negative control, consisting of a pool of non-infected mosquitoes from the same species and generation. Normalised data were used to measure the number of RNA copies in mosquitoes according to the $\Delta \mathrm{C}$ analysis. A CHIKV RNA synthetic transcript was used as a positive control at two concentrations: $10^{2}$ and $10^{5}$ RNA copies.

\section{RESULTS}

Assay A - Progenies from the first gonotrophic cycle were collected from 107 females (Table). Eggs were collected from days 3-29 post-infection, with a majority of females (50) laying their first eggs on day 6 postinfection; 13 laid their eggs on day 3 and the remainder did so after day 6 post-infection. Immunofluorescence 
assays performed on head squashes of all 1,675 descendants were negative. No viral RNA was detected in the bodies of these samples.

Assay $B$ - Progenies from the second gonotrophic cycle were collected from 94 females (Table). Eggs were collected from days 4-21 post-infection. The first eggs were laid between days 4-6 post-infection, i.e., 81 females laid their first eggs on day 4, 7 on day 5 and 6 on day 6 post-infection. No viral RNA was detected in the 1,709 descendants.

\section{TABLE}

Progeny of Aedes albopictus females (assay A and assay B) infected with chikungunya virus 06.21 from La Réunion Island

\begin{tabular}{lcc}
\hline & Assay $\mathrm{A}^{a}$ & Assay B $^{b}$ \\
\hline Mothers (n) & 107 & 94 \\
First eggs & day 3 pi & day 4 pi \\
Last eggs & day 29 pi & day 21 pi \\
Descendants per female (n) & $1-66$ & $1-78$ \\
Males (n/pools) & $754(119)$ & $820(126)$ \\
Females (n/pools) & $921(118)$ & $889(137)$ \\
Total descendants (n) & 1,675 & 1,709 \\
\hline
\end{tabular}

$a$ : gonotrophic cycle $1 ; b$ : gonotrophic cycle 2 ; pi: post-infection.

\section{DISCUSSION}

Vertical transmission has long been suspected to be the mechanism by which CHIKV could be maintained in nature, thereby explaining its cyclic re-emergence in the absence of a sylvatic cycle. However, previous studies have failed to demonstrate this phenomenon in Aedes furcifer and Ae. aegypti formosus from South Africa (Jupp et al. 1981) and in Ae. aegypti and Ae. albopictus from India (Mourya 1987). Tesh (1984) noted that, in contrast to the other arbovirus groups, little field or experimental evidence suggested the possible vertical transmission of alphaviruses. However, the first emergence of CHIKV in the Indian Ocean, as well as the unusual implication of Ae. albopictus as the main vector responsible for the massive outbreak in La Réunion, raised concerns about a possible maintenance of the virus during the dry season. Therefore, specimens were collected in the field in La Réunion in 2006 and a low rate of vertical transmission was detected (Delatte et al. 2008). In the same year in Madagascar, the presence of CHIKV RNA was also detected in Ae. albopictus but no infectious viral particle was recovered from these samples (Ratsitorahina et al. 2008). To try to elucidate this situation, we decided to conduct vertical transmission experiments with a strain of Ae. albopictus from La Réunion and the CHIKV epidemic strain (CHIKV 06.21). As for previous authors, we were unable to detect vertical transmission despite the use of a very high dose of infectious particles in the infectious blood-meal and the very high load of infectious particles detected in mothers (i.e., infected females)
(Vazeille et al. 2007). However, our negative results are not surprising considering the low rate of vertical transmission described in Delatte et al. (2008), i.e., two positive pools out of 6,853 individuals. Thus the minimum infection rate for field records was then two out of 6,853 , not significantly different from the results of our laboratory study performed on 3,384 mosquitoes ( $p>0.05$, Fisher's exact test). In experimental vertical transmission experiments, it is usual to adopt the best conditions allowing the highest survival rate of infected females, such as plenty of food at the larval stage to obtain large size females, maximum humidity and suitable temperature during the incubation period of adult females, appropriate photoperiod. Although they may be favourable to the survival of the vector, these optimal conditions may not be ideal for the transmission of the virus to the progeny. We observed a high load of viral particles in the eggs, but the infection was obviously not transmitted to the next generation or was cleared during the early stages of development.

In conclusion, the negative results we obtained and the low rates observed in the field lead us to think that vertical transmission of CHIKV has not played a key role in the maintenance of the virus in La Réunion. The re-introduction of the virus by infected humans is more likely to be the cause of a putative new outbreak.

\section{ACKNOWLEDGEMENTS}

To the Direction Régionale des Affaires Sanitaires et Sociales (DRASS) from La Réunion, for providing the Aedes albopictus eggs of the Providence strain.

\section{REFERENCES}

Delatte H, Paupy C, Dehecq JS, Thiria J, Failloux AB, Fontenille D 2008. Aedes albopictus, vecteur des virus du chikungunya et de la dengue à la Réunion: biologie et contrôle. Parasite 15: 3-13.

Diallo M, Thonnon J, Traoré-Lamizana M, Fontenille D 1999. Vectors of chikungunya virus in Senegal: current data and transmission cycles. Am J Trop Med Hyg 60: 281-286.

Igarashi A 1978. Isolation of a Singh's Aedes albopictus cell clone sensitive to dengue and chikungunya viruses. J Gen Virol 40: 531-544.

Jupp PG, Kemp A 1996. What is the potential for future outbreaks of chikungunya, dengue and yellow fever in Southern Africa? S Afr Med J 86: 35-37.

Jupp PG, McIntosh BM 1988. Chikungunya virus diseases. In TP Monath, The arboviruses: epidemiology and ecology, Vol. II, CRC Press, Boca Raton, Florida, p. 137-157.

Jupp PG, McIntosh BM, Dos Santos I 1981. Laboratory vector studies on six mosquito and one tick species with chikungunya virus. Trans R Soc Trop Med 75: 15-19.

Kuberski TT, Rosen L 1977. A simple technique for the detection of dengue antigen in mosquitoes by immunofluorescence. $A m J$ Trop Med Hyg 26: 533-537.

Mourya DT 1987. Absence of transovarial transmission of chikungunya virus in Aedes aegypti \& Ae. albopictus mosquitoes. Indian J Med Res 85: 593-595.

Ratsitorahina M, Harisoa J, Ratovonjato J, Biacabe S, Reynes JM, Zeller H, Raoelina Y, Talarmin A, Richard V, Soares JL 2008. Outbreak of dengue and chikungunya fevers, Toamasina, Madagascar, 2006. EID 14: 1135-1137. 
Renault P, Solet JL, Sissoko D, Balleydier E, Larrieu S, Filleul L, Lassalle C, Thiria J, Rachou E, de Valk H, Ilef D, Ledrans M, Quatresous I, Quenel P, Pierre V 2007. A major epidemic of chikungunya virus infection on Réunion Island, France, 2005-2006. Am J Trop Med Hyg 77: 727-731.

Ross RW 1956. The Newala epidemic. III. The virus: isolation, pathogenic properties and relationship to the epidemic. J Hyg 54: 177-191.

Salvan M, Mouchet J 1994. Aedes albopictus et Aedes aegypti à l'lle de la Réunion. Ann Soc Belge Med Trop 74: 323-326.

Schuffenecker I, Iteman I, Michault A, Murri S, Frangeul L, Vaney MC, Lavenir R, Pardigon N, Reynes JM, Pettinelli F, Biscornet L, Diancourt L, Michel S, Duquerroy S, Guigon G, Frenkiel MP, Bréhin AC, Cubito N, Desprès P, Kunst F, Rey FA, Zeller H, Brisse S 2006. Genome microevolution of chikungunya viruses causing the Indian Ocean outbreak. PloS Med 3: e263.
Tesh RB 1984. Transovarial transmission of arboviruses in their invertebrate vectors. In KF Harris, Current topics in vector research, Vol. II, Praeger, New York, p. 57-76.

Tsetsarkin KA, Vanlandingham DL, Mc Gee CE, Higgs S 2007. A single mutation in chikungunya virus affects vector specificity and epidemic potential. PLoS Pathogens 12: e201.

Vazeille M, Moutailler S, Coudrier D, Rousseaux C, Khun H, Huerre M, Thiria J, Dehecq JS, Fontenille D, Schuffenecker I, Desprès P, Failloux AB 2007. Two Chikungunya isolates from the outbreak of La Réunion (Indian Ocean) exhibit different patterns of infection in the mosquito, Aedes albopictus. PLoS One 11: e1168.

Vazeille-Falcoz M, Mousson L, Rodhain F, Chungue, Failloux AB 1999. Variation in oral susceptibility to dengue type 2 virus of populations of Aedes aegypti from the islands of Tahiti and Moorea, French Polynesia. Am J Trop Med Hyg 60: 292-299. 